\title{
Analysis of the Single Toggle Jaw Crusher Force Transmission Characteristics
}

\author{
Moses Frank Oduori, David Masinde Munyasi, and Stephen Mwenje Mutuli \\ Department of Mechanical and Manufacturing Engineering, The University of Nairobi, P.O. Box 30197, Nairobi 00100, Kenya
}

Correspondence should be addressed to Moses Frank Oduori; foduori@uonbi.ac.ke

Received 9 June 2016; Revised 6 November 2016; Accepted 14 November 2016

Academic Editor: Yuh-Shyan Hwang

Copyright (C) 2016 Moses Frank Oduori et al. This is an open access article distributed under the Creative Commons Attribution License, which permits unrestricted use, distribution, and reproduction in any medium, provided the original work is properly cited.

\begin{abstract}
This paper sets out to perform a static force analysis of the single toggle jaw crusher mechanism and to obtain the force transmission characteristics of the mechanism. In order to obtain force transmission metrics that are characteristic of the structure of the mechanism, such influences as friction, dead weight, and inertia are considered to be extraneous and neglected. Equations are obtained by considering the balance of forces at the moving joints and appropriately relating these to the input torque and the output torque. A mechanical advantage, the corresponding transmitted torque, and the variations thereof, during the cycle of motion of the mechanism, are obtained. The mechanical advantage that characterizes the mechanism is calculated as the mean value over the active crushing stroke of the mechanism. The force transmission characteristics can be used as criteria for the comparison of different jaw crusher mechanism designs in order to select the most suitable design for a given application. The equations obtained can also be used in estimating the forces sustained by the components of the mechanism.
\end{abstract}

\section{Introduction}

The literature on kinematics and mechanism design identifies three tasks for which linkage mechanisms are commonly designed and used, namely, function generation, motion generation, which is also known as rigid body guidance, and path generation [1-3]. Way back in 1955, Freudenstein, who is widely regarded as the father of modern Kinematics of Mechanisms and Machines, introduced an analytical method for the design of a four-bar planar mechanism for function generation [4]. Wang et al. presented a study on the synthesis of planar linkage mechanisms for rigid body guidance [5]. An interesting design and application of a planar four-bar mechanism for path generation was reported by Soong and $\mathrm{Wu}[6]$. In general, the use of linkage mechanisms involves the transmission and transformation of motions and forces. In practical applications, linkage mechanisms appear to be more commonly designed and used for the transmission and transformation of motions rather than forces. In such cases, the transmitted forces are quite small.

The jaw crusher happens to be an example of a planar linkage application that is designed and used for the transmission and transformation of motions but also has to transmit, transform, and apply the large forces that are required to crush hard rocks by compression. Therefore it is important to understand the force transmission characteristics of the jaw crusher mechanism and to be able to use them for sound mechanical design of the crusher.

Today, the most commonly used types of jaw crusher are the single toggle and the double toggle designs. The original double toggle jaw crusher was designed by Eli Whitney Blake in the USA in 1857 [7]. The motion of the swing jaw in a double toggle crusher is such that it applies an almost purely compressive force upon the material being crushed. This minimizes wear on the crushing surfaces of the jaws and makes the double toggle jaw crusher suitable for crushing highly abrasive and very hard materials. Even today, the Blake design, with some comparatively minor improvements, can still be found in mines and quarries around the world.

The single toggle design, which was developed between the 1920s and the 1950s, is a simpler, lighter crusher [7]. Its swing jaw has a rolling elliptical motion such that it applies a compressive as well as a rubbing force on the material being crushed. This has a force-feeding effect that improves the throughput of the device, but it also tends to cause rapid wear 
of the crushing surfaces of the jaws. However, the single toggle jaw crusher has a lower installed cost, as compared to the double toggle design. Improvements in materials and design have made the single toggle jaw crusher more common today as the primary crusher in quarrying operations [8]. According to Carter Russell [9], in 1999 sales of the single toggle jaw crusher exceeded those of the double toggle jaw crusher by a factor of at least nine to one.

This paper performs a static force analysis of the single toggle jaw crusher mechanism. As a result of this analysis, a characteristic force transmission ratio, which may be regarded as a mechanical advantage of the mechanism, is derived. This ratio can be used as a criterion for the comparison of different jaw crusher mechanism designs, with a view to selecting the most suitable design for use in a given application.

\section{Literature Review}

Over time, several authors have addressed the static force analysis of the double toggle jaw crusher mechanism. Among the earlier of such efforts is that of Ham et al. [10], who performed a static force analysis of the double toggle jaw crusher mechanism in order to determine the input turning moment that would be required to overcome a known crushing resistance of the material being crushed. They used a graphical method to carry out the analysis.

In discussing linkages, Martin [11] featured the double toggle jaw crusher mechanism as an example of a machine that uses the toggle effect to obtain a large output force that acts through a short distance, but he did not perform a static force analysis of the mechanism.

Erdman and Sandor [1] presented the determination of the mechanical advantage of a double toggle jaw crusher mechanism, as an exercise problem to be solved by

(1) the method of instant centres, which is essentially a graphical method;

(2) an analytical method that utilized complex number representation of vectors.

Norton [2] also discussed the mechanical advantage of linkage mechanisms and explained the toggle effect by the use of a jaw crusher mechanism of the Dodge type [8].

More generally, Lin and Chang [12] addressed the issue of force transmissivity in planar linkage mechanisms. They derived and proposed a force transmissivity index (FTI) that considered the power flow path from the input linkage to the output linkage. They calculated the effective force ratio (EFR) as the ratio of the sum of actual power transmitted at each of the linkage joints in the power flow path to the sum of the maximum possible power that could be transmitted along the same power flow path. They then obtained the FTI as the product of the EFR and the mechanical advantage of the mechanism, thus taking into account the effect of the external load acting on the mechanism. They compared their results to other indices of force transmissivity, such as the Jacobian matrix method [13] and the joint force index (JFI) [14], and found their FTI to be more accurate. Furthermore, the Jacobian matrix method does not consider the effect of the external load while the JFI does not consider the power flow path in the mechanism.

The method used by Lin and Chang [12] involves a static force analysis and the determination of velocities at the joints within the power flow path. Subsequently, Chang et al. [15] extended and applied this method to parallel manipulators, defined, and proposed a mean force transmission index (MFTI). The presentation here will perform a static force analysis and obtain the mechanical advantage of the single toggle jaw crusher mechanism, from first principles.

\section{Methodology}

According to Ham et al. [10], analysis of forces in any machine is based on the fundamental principle which states that "the system composed of all external forces and all the inertia forces that act upon any given member of the machine is a system that is in equilibrium."

For a planar mechanism, such as the single toggle jaw crusher, it is customary to treat the forces as if they are coplanar, at least in the initial analysis. The effects of the offsets between the planes of action of the forces can then be revisited at a later stage of analysis and design. The assumption of coplanar forces will be employed in this presentation.

In the static force analysis of a machine, the forces arising due to the accelerations of the machine members are neglected. These forces are taken into account in a dynamic force analysis, which can be done, meaningfully, after the forms and masses of the machine members have been determined. Frictional forces may be taken into account in a static force analysis [16], but in the present case, it shall be assumed that the use of antifriction bearings in the revolute joints reduces frictional forces to negligible levels.

Furthermore, this presentation aims to obtain an indicator of the efficacy of force transmission, in the single toggle jaw crusher, that may be attributed to the structure of the mechanism per se. Therefore, frictional and inertia forces may be regarded as extraneous to this purpose and will not be included in this analysis.

In a planar four-bar mechanism with four revolute joints, which can be denoted by $R R R R$ or $4 R$, the efficacy of force transmission has often been expressed by what is known as the transmission angle $[2,3,11,17]$. This works well enough if, for instance, the mechanism is a crank-and-rocker, in which the crank is the input link and the rocker is the output link. Then, the transmission angle becomes the acute angle between the rocker and the coupler, and, indeed, its value indicates the efficacy of force transmission in the mechanism.

The single toggle jaw crusher mechanism can be modelled as a planar $4 R$ mechanism, as shown in Figure 1. However, in this mechanism, it is the coupler that is the output link and the transmission angle, as defined in the above cited literature, fails to be a suitable indicator of the efficacy of force transmission. Therefore, a better indicator of the efficacy of force transmission in the single toggle jaw crusher is sought in this paper. 


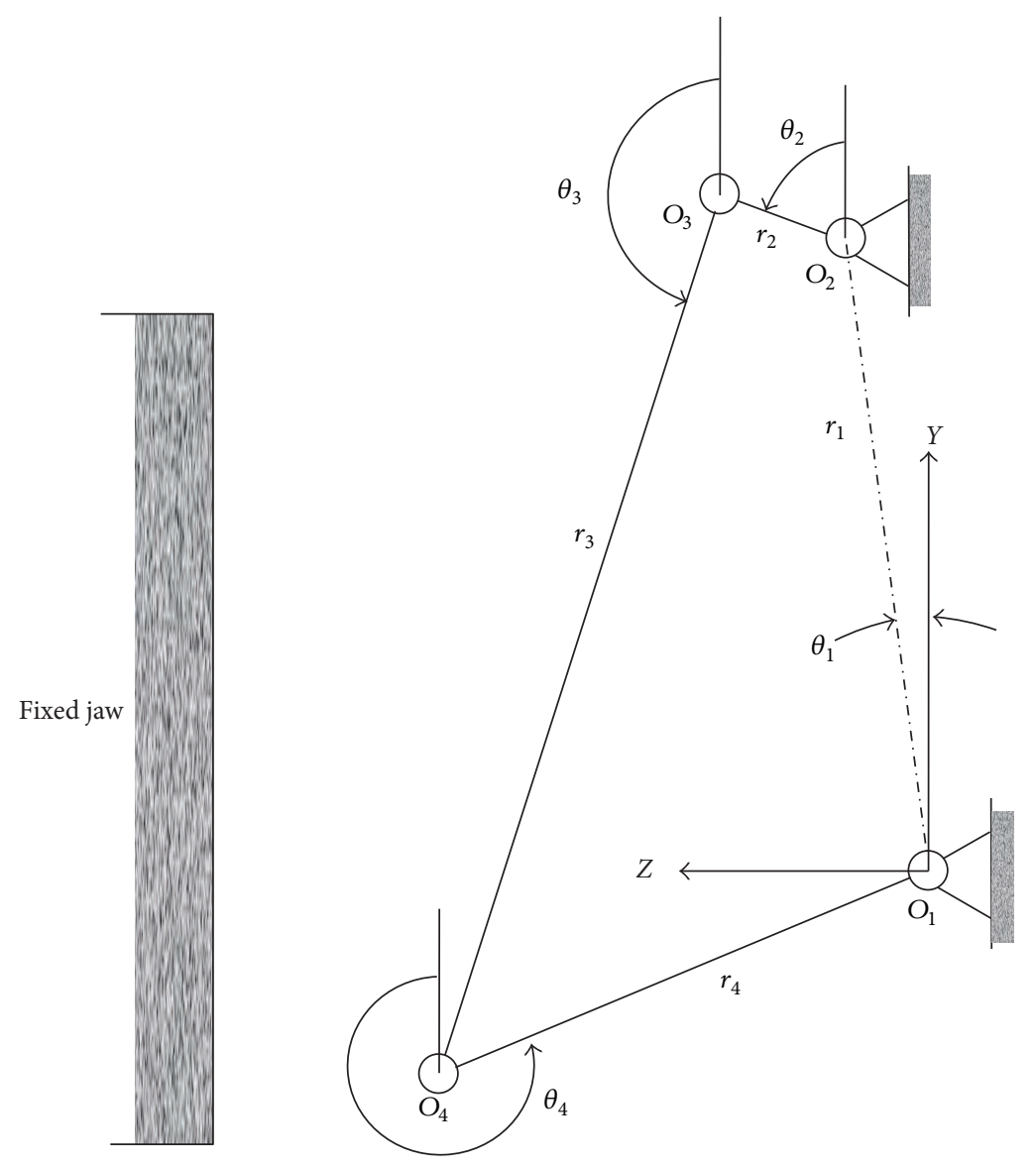

FIGURE 1: Kinematical model of the single toggle jaw crusher.

Erdman and Sandor [1], Norton [2], and Shigley and Uicker Jr. [3] presented methods for determining the mechanical advantage of planar $4 R$ mechanisms that make the assumption of $100 \%$ mechanical efficiency for the mechanism and find the mechanical advantage of the mechanism to be inversely proportional to the output-to-input angular velocity ratio. The presentation by Shigley and Uicker Jr. [3] defined the mechanical advantage as the ratio of the output torque to the input torque, which led to a slightly different expression for the mechanical advantage, as compared to Erdman and Sandor [1] and Norton [2], who defined mechanical advantage as the ratio of output force to input force.

The methods presented by Erdman and Sandor [1], Norton [2], and Shigley and Uicker Jr. [3] give no indication of the actual forces that are sustained by the members of the mechanism, knowledge of which would be necessary at the design stage.

The method used in this paper includes the following:

(i) A static force analysis that neglects the frictional and inertia forces is performed.

(ii) All the forces and moments are assumed to be coplanar.

(iii) The analysis proceeds by considering the equilibrium of the forces acting at the moving joints of the mechanism and relating them to the input torque as well as the load torque. This may be compared to the method presented by Abhary [18].

The method used here is systematic and therefore clear and simple to follow and to use. As a result of the analysis, a characteristic mechanical advantage of the single toggle jaw crusher mechanism is obtained, which may be used as a criterion for selecting such mechanisms.

\section{A Review of the Single Toggle Jaw Crusher Kinematics}

In the kinematical model of the single toggle jaw crusher, which is illustrated in Figure 1, the eccentric shaft is modelled as a short crank, of length $r_{2}$, that continuously rotates about a fixed axis, at $\mathrm{O}_{2}$. The swing jaw is modelled as the coupler link $\mathrm{O}_{3} \mathrm{O}_{4}$, of length $r_{3}$, which moves with a complex planar motion that has both rotational and translational components. The toggle link is modelled as the rocker $\mathrm{O}_{4} \mathrm{O}_{1}$, which oscillates about the fixed axis at $O_{1}$. The fixed jaw is considered to be an integral part of the frame of the machine.

Oduori et al. [19] analysed the kinematics of the single toggle jaw crusher, as modelled in Figure 1, and found the following expression:

$$
\begin{aligned}
& 2 r_{1} r_{2} \cos \left(\theta_{2}-\theta_{1}\right)+2 r_{2} r_{3} \cos \left(\theta_{3}-\theta_{2}\right) \\
& \quad+2 r_{3} r_{1} \cos \left(\theta_{3}-\theta_{1}\right)=r_{4}{ }^{2}-r_{3}{ }^{2}-r_{2}{ }^{2}-r_{1}{ }^{2} .
\end{aligned}
$$


TABLE 1: Data for a PE 400 by 600 single toggle jaw crusher (mm).

\begin{tabular}{lcccc}
\hline$r_{1} \sin \theta_{1}$ & $r_{1} \cos \theta_{1}$ & $r_{2}$ & $r_{3}$ & $r_{4}$ \\
\hline 45.3 & 815.7 & 12 & 1085 & 455 \\
\hline
\end{tabular}

Cao et al. [20] used the dimensional data for a PE $400 \times 600$ single toggle jaw crusher, as shown in Table 1.

From the data in Table 1, it follows, to good approximation, that $r_{1}=817 \mathrm{~mm}$ and $\theta_{1}=3.18^{\circ}$. We shall adopt these data as we proceed.

By substituting the data given in Table 1, into equation (1), the following is obtained:

$$
\begin{aligned}
& 0.753 \cos \left(\theta_{2}-3.18^{\circ}\right)+\cos \left(\theta_{3}-\theta_{2}\right) \\
& +68.08 \cos \left(\theta_{3}-3.18^{\circ}\right)=-62.894 .
\end{aligned}
$$

Equation (2) can be used to determine values of $\theta_{3}$ for any given value of $\theta_{2}$, which represents the input motion.

In the cycle of motion of the single toggle jaw crusher mechanism, two phases, known as the toggle phases, are of particular interest. In each of the toggle phases, the crank and the coupler link fall on a single straight line. Therefore, the toggle phases occur when $\theta_{2}=\theta_{3}$ and when $\theta_{2}=\theta_{3}+180^{\circ}$. For the first toggle phase, equation (2) can be reduced to the following:

$$
68.833 \cos \left(\theta_{2}-3.18^{\circ}\right)=-63.894 .
$$

Equation (3) is readily solved to give $\theta_{2}=161.34^{\circ}$ for the first toggle phase.

Similarly, for the second toggle phase, equation (2) can be reduced to the following:

$$
67.327 \cos \left(\theta_{2}-3.18^{\circ}\right)=61.894 .
$$

Equation (4) too is readily solved to give $\theta_{2}=340^{\circ}$ for the second toggle phase.

\section{Force Transmission Model}

The forces and moments acting upon the links of the single toggle jaw crusher mechanism are all assumed to be coplanar and illustrated in Figure 2.

In performing the static force analysis it shall be assumed that the masses of the links, as well as friction forces, are negligible. The effects of these forces can be considered at a later stage in the design of the mechanism. In Figure 2, $T_{2}$ is the driving torque, applied at the crank axis $\mathrm{O}_{2}$, to drive the crank and the entire crusher mechanism. $T_{3}$ is the torque, acting about the axis of joint $\mathrm{O}_{3}$, due to the resistance of the feed material against being crushed. $F_{2}, F_{3}$, and $F_{4}$ are the forces in links 2,3 , and 4 , respectively, and they are all assumed to be compressive. The system of forces and moments is assumed to be in equilibrium in every phase of motion of the mechanism.

\section{Static Force Analysis}

The forces acting at the moving joints $\mathrm{O}_{3}$ and $\mathrm{O}_{4}$ are shown in Figure 3.
Let us start by considering the crank. Static force analysis is based on the assumption that there are no accelerations in the mechanism. Referring to Figures 1, 2, and 3, the equilibrium of moments acting on the crank, about the fixed joint $\mathrm{O}_{2}$, leads to the following result:

$$
\begin{aligned}
0 & =-F_{Y 32} r_{2} \sin \theta_{2}-F_{Z 32} r_{2} \cos \theta_{2}+T_{2}, \\
T_{2} & =\left[F_{Z 32} \cos \theta_{2}+F_{Y 32} \sin \theta_{2}\right] r_{2} .
\end{aligned}
$$

Next let us consider the coupler. The equilibrium of forces at joint $\mathrm{O}_{3}$ leads to the following:

$$
\begin{aligned}
F_{Y 23}+F_{3} \cos \left(180^{\circ}-\theta_{3}\right) & =0, \\
F_{Y 23} & =F_{3} \cos \theta_{3}, \\
F_{Y 32} & =-F_{Y 23}=-F_{3} \cos \theta_{3}, \\
F_{Z 23}+F_{3} \sin \left(180^{\circ}-\theta_{3}\right) & =0, \\
F_{Z 23} & =-F_{3} \sin \theta_{3}, \\
F_{Z 32} & =-F_{Z 23}=F_{3} \sin \theta_{3} .
\end{aligned}
$$

From equations (5) and (6), it follows that

$$
\begin{aligned}
T_{2} & =\left(F_{3} \sin \theta_{3} \cos \theta_{2}-F_{3} \cos \theta_{3} \sin \theta_{2}\right) r_{2} \\
& =F_{3} r_{2} \sin \left(\theta_{3}-\theta_{2}\right) .
\end{aligned}
$$

The statement in equation (7) is illustrated in Figure 4.

Moreover, it should be evident from Figures 3 and 4 that

$$
F_{3} \cos \left(\theta_{3}-\theta_{2}\right)=-F_{2} \text {. }
$$

Now, in Figure 3, by considering the equilibrium of all the forces acting upon the coupler, the following is obtained:

$$
\begin{aligned}
F_{Y 43}+F_{Y 23} & =0, \\
F_{Y 43} & =-F_{Y 23}=-F_{3} \cos \theta_{3}, \\
F_{Z 43}+F_{Z 23} & =0, \\
F_{Z 43} & =-F_{Z 23}=F_{3} \sin \theta_{3} .
\end{aligned}
$$

Moreover, in Figure 3, the equilibrium of moments acting on the coupler, about the joint $\mathrm{O}_{3}$, leads to the following result:

$$
\begin{aligned}
0 & =-F_{Y 43} r_{3} \sin \theta_{3}+F_{Z 43} r_{3} \cos \theta_{3}+T_{3}, \\
T_{3} & =\left[F_{Y 43} \sin \theta_{3}-F_{Z 43} \cos \theta_{3}\right] r_{3} .
\end{aligned}
$$

From equations (9) and (10), it follows that

$$
T_{3}=-F_{3} r_{3} \sin \left(2 \theta_{3}\right) \text {. }
$$

A relationship between $T_{3}$ and $T_{2}$ can now be obtained from equations (7) and (11), as follows:

$$
f\left(\theta_{2}\right)=\frac{T_{3} r_{2}}{T_{2} r_{3}}=-\frac{\sin \left(2 \theta_{3}\right)}{\sin \left(\theta_{3}-\theta_{2}\right)} .
$$




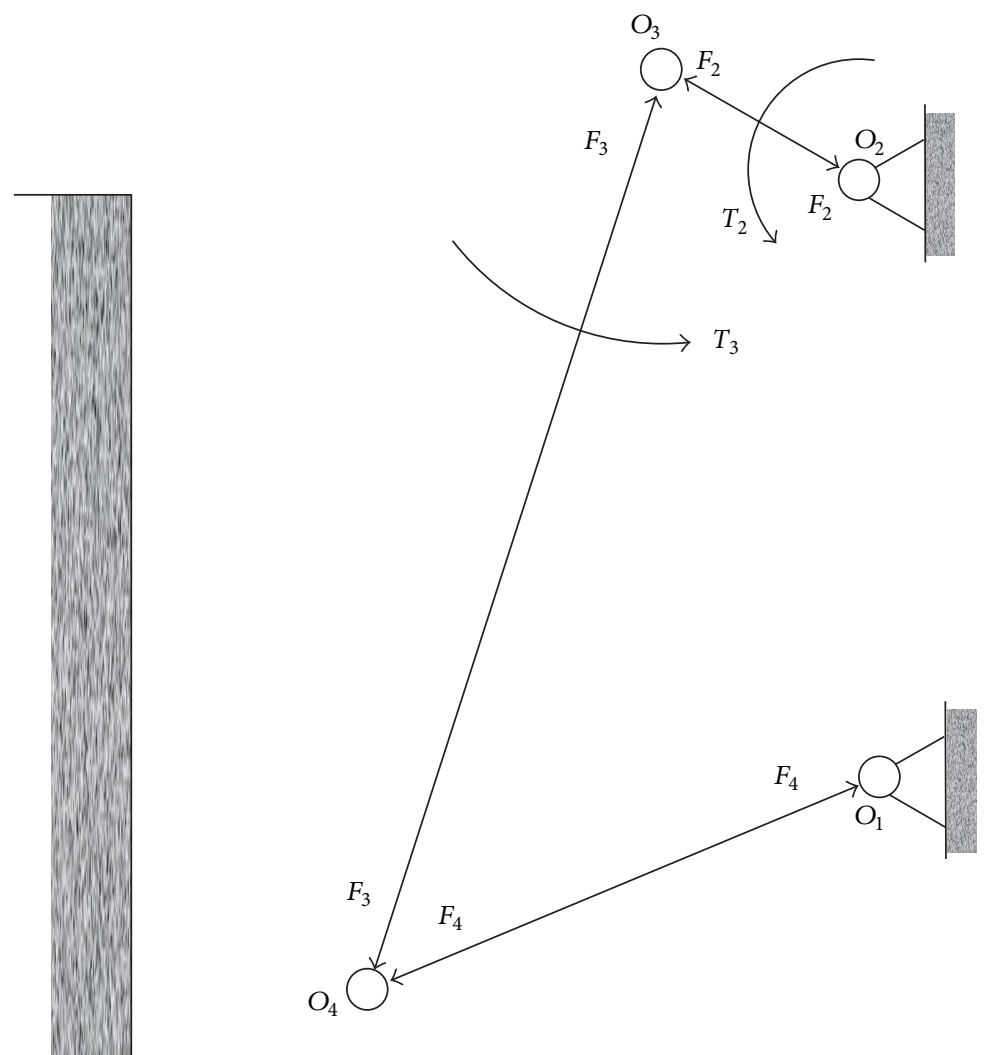

Figure 2: Model for static force analysis of the single toggle jaw crusher.

Equation (12) is in dimensionless form. The left-hand side of this equation can be regarded as a force transmission ratio that compares the nominal transmitted force, $T_{3} / r_{3}$, to the nominal input force, $T_{2} / r_{2}$. This ratio is an indicator of the theoretical force transmission potential for any given phase of motion of the mechanism.

For a given crusher mechanism, the values of $\theta_{2}$ and $\theta_{3}$ can be determined from purely kinematical considerations, by the use of (1) along with the dimensional data of the mechanism, and then the value of the right-hand side of (12) will be determined.

Using the dimensional data of the mechanism, given in Table 1, along with given values of $\theta_{2}$, the corresponding values of $\theta_{3}$ were computed and then used in (12) to determine the corresponding force transmission ratios, for one and a half cycles of motion of the crank. The results are plotted in Figure 5.

The first spike in Figure 5 indicates the great amplification of the crushing force that occurs at the first toggle position, which corresponds to a crank angle of about $161.34^{\circ}$. Theoretically, the crushing force amplification should be infinite at this toggle phase. Moreover, there occurs an abrupt reversal of the sign of the force transmission ratio from positive to negative, at this toggle phase. The second spike in Figure 5, which is also accompanied by a reversal in the sign of the force transmission ratio, occurs at a crank angle of about $340^{\circ}$. This spike corresponds to the second toggle phase of the mechanism.

The great amplification of transmitted force, accompanied by the abrupt reversal of the sign of the force transmission ratio, at each of the toggle phases, may be compared with the phenomenon of resonance, in mechanical vibrations, which also features great amplification of the responding motion, accompanied by a reversal of the phase between the forcing and the responding functions.

As the crank rotates from $\theta_{2}=161.34^{\circ}$ to $\theta_{2}=340^{\circ}$, the crusher would be on the idle stroke with the swing jaw being retracted and no work being done in crushing the feed material. This is evidenced by the negative values of the force transmission ratio, between these two angular positions of the crank, in Figure 5. Useful work is done as the crank rotates from $\theta_{2}=340^{\circ}$ to $\theta_{2}=521.34^{\circ}$, in a succeeding cycle of motion of the crank. Thus, during each cycle of motion of the crank, the useful working stroke of the mechanism lasts for about $181.34^{\circ}$ of rotation of the crank, which is very slightly greater than half the cycle of motion of the crank. On the other hand, during each cycle of motion of the crank, the idle stroke lasts for $178.66^{\circ}$ of rotation of the crank, which is very slightly less than half the cycle of motion of the crank.

Thus, the mechanism has a quick return feature that is hardly noticeable since the crushing stroke lasts for $50.37 \%$ of the complete cycle of its motion, while the idle stroke lasts for $49.63 \%$ of the complete cycle of the motion of the mechanism. 

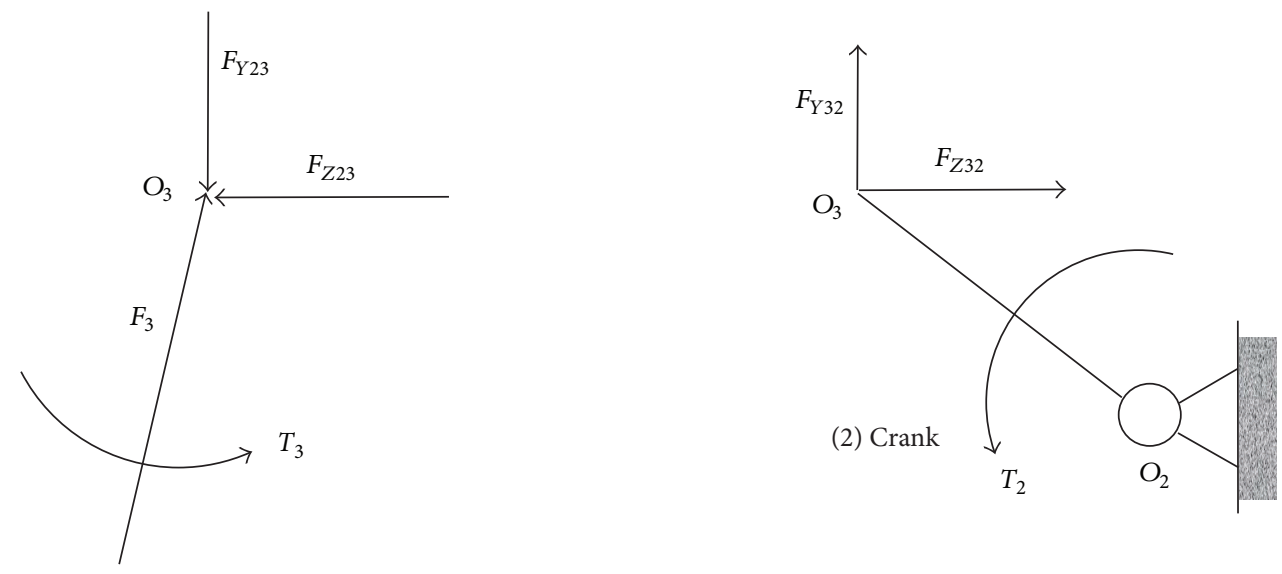

(3) Coupler
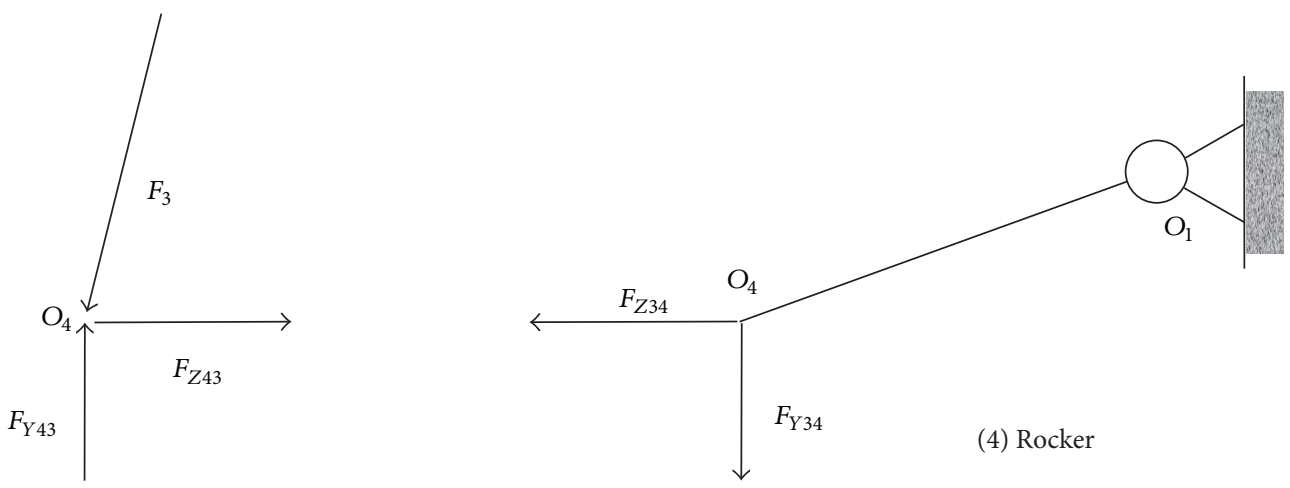

FIGURE 3: Free-body diagrams of the crank, the coupler, and the rocker.

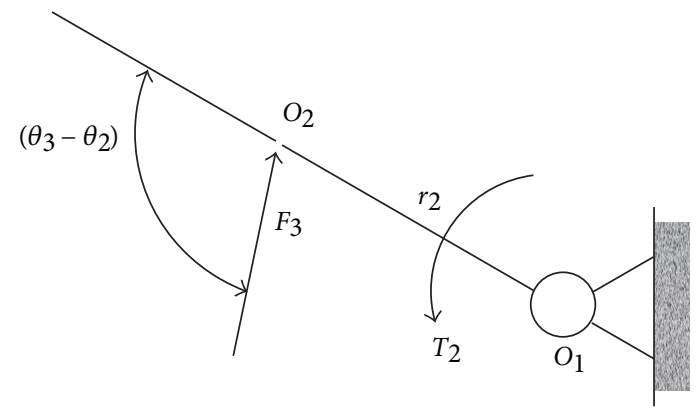

(2) Crank

FIgURE 4: Balance of moments on the crank.

\section{Results and Discussion}

7.1. Force Transmission Ratio and the Transmitted Torque. In the preceding section, we have seen that the crushing stroke lasts for only about $50 \%$ of each complete cycle of motion of the single toggle jaw crusher. For the other $50 \%$ of the

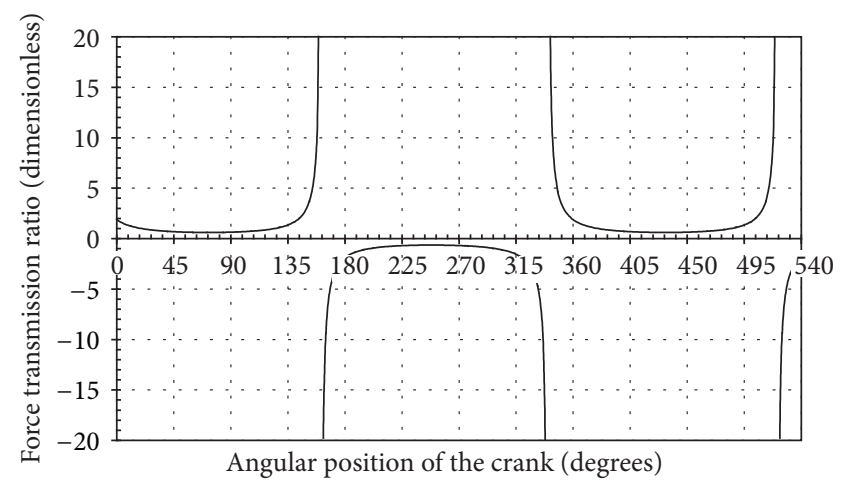

FIGURE 5: Variation of force transmission ratio with crank angle $\theta_{2}$.

complete cycle of motion, the swing jaw is being retracted in preparation for the next crushing stroke.

Moreover, in Figure 5, it can be seen that the force transmission ratio varies from a very high value, at the beginning of the crushing stroke, that initially falls very rapidly and then levels off to reach a minimum value of less that unity (about 
TABLE 2: Sample values of force transmission ratio during the crushing stroke.

\begin{tabular}{lc}
\hline$\theta_{2}$ (degrees) & Force transmission ratio, $f\left(\theta_{2}\right)$ (dimensionless) \\
\hline 340 & $2,418.327$ \\
350 & 4.649 \\
360 & 1.882 \\
370 & 1.280 \\
380 & 0.989 \\
390 & 0.823 \\
400 & 0.772 \\
410 & 0.660 \\
420 & 0.624 \\
430 & 0.609 \\
440 & 0.612 \\
450 & 0.636 \\
460 & 0.684 \\
470 & 0.766 \\
480 & 0.904 \\
490 & 1.148 \\
500 & 1.642 \\
510 & 3.046 \\
520 & 26.030 \\
521.31 & $3,268.45$ \\
\hline
\end{tabular}

0.6 ), about halfway through the crushing stroke. The latter half of the crushing stroke appears to be a mirror image of the earlier half, in which the force transmission ratio first rises gradually and then spikes to a very high value at the end of the crushing stroke. Sample values of the force transmission ratio during the useful crushing stroke are given in Table 2.

The fact that the crushing stroke commences with a very high value of the force transmission ratio is advantageous when crushing brittle material, which is often the case. Since brittle materials fracture without undergoing significant deformation, actual crushing of brittle materials in a single toggle jaw crusher would occur soon after commencement of the crushing stroke, where the force transmission ratio is high.

According to Chinese jaw crusher manufacturer's data [21], the PE 400 by 600 single toggle jaw crusher has $30 \mathrm{~kW}$ motor power and an input eccentric shaft speed of $275 \mathrm{rpm}$ or 28.7979 radians per second. Assuming that the input speed is constant, the input torque is found to be $1.0417 \mathrm{kNm}$. By using this information, along with the data in Table 1 and (12), the transmitted torque, in kilonewton-metres, can be estimated to be the following:

$$
T_{3}=-94.19\left[\frac{\sin \left(2 \theta_{3}\right)}{\sin \left(\theta_{3}-\theta_{2}\right)}\right] .
$$

The above calculation assumes a $100 \%$ power transmission efficiency. Equation (13) was used to calculate the values of the transmitted torque that are given in Table 3.

The above calculations reveal that the minimum value of the transmitted torque will be about 55 times as big as the input torque, with the theoretical maximum value being
TABLE 3: Sample values of the transmitted torque during the crushing stroke.

\begin{tabular}{lc}
\hline$\theta_{2}$ (degrees) & Transmitted torque, $T_{3}$ (kilonewton-metres) \\
\hline 340 & $227,784.124$ \\
350 & 350.770 \\
360 & 196.420 \\
370 & 120.544 \\
380 & 93.110 \\
390 & 77.544 \\
400 & 68.000 \\
410 & 62.120 \\
420 & 58.741 \\
430 & 57.325 \\
440 & 57.685 \\
450 & 59.917 \\
460 & 64.441 \\
470 & 72.195 \\
480 & 85.183 \\
490 & 108.106 \\
500 & 154.632 \\
510 & 286.930 \\
520 & 2451.743 \\
521.31 & $307,857.521$ \\
\hline
\end{tabular}

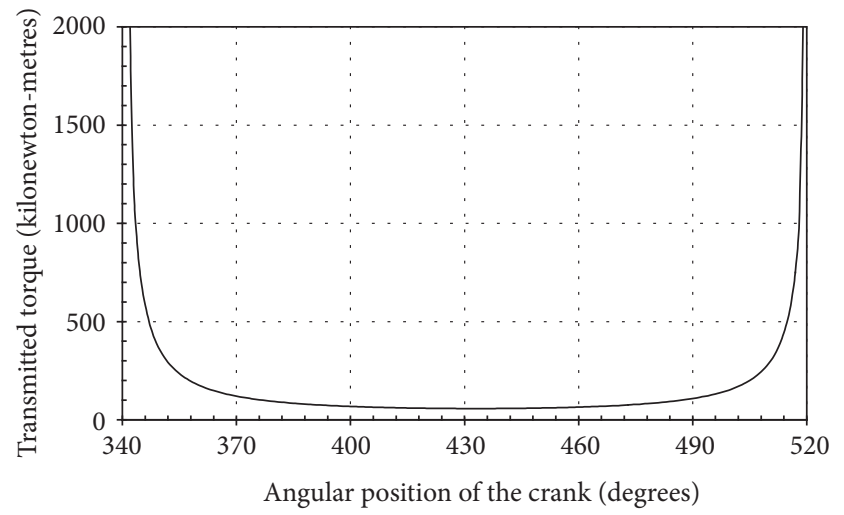

FIGURE 6: Variation of transmitted torque during a crushing stroke.

infinity. This is why a material that cannot be crushed will lead to breakage of the toggle link.

The values of the transmitted torque, as calculated by the use of (13), are plotted in Figure 6, for one complete active crushing stroke.

7.2. Characteristic Mechanical Advantage. A force transmission ratio that would characterize the single toggle jaw crusher was calculated as the mean value of the force transmission ratio over a complete useful crushing stroke, which does not include the retraction stroke.

According to the Mean Value Theorem of the integral calculus [22], if a function $y=f(x)$ is continuous on the closed 
TABLE 4: Force transmission characteristics of the single toggle jaw crusher.

\begin{tabular}{lcc}
\hline Characteristics & Value (dimensionless) & Corresponding crank angle (degrees) \\
\hline Minimum force transmission ratio & 0.608 & 433 \\
Maximum force transmission ratio & 3268.446 & 521.31 \\
Mean force transmission ratio & 10.581 & Nonapplicable \\
\hline
\end{tabular}

interval $[a, b]$, then the mean value of $y$ for that interval can be determined as follows:

$$
\bar{y}=\frac{1}{b-a} \int_{a}^{b} f(x) \mathrm{d} x .
$$

In determining the characteristic mechanical advantage, the mean value of the force transmission ratio was determined as follows:

$$
\bar{f}\left(\theta_{2}\right)=\frac{1}{181.31^{\circ}} \int_{340^{\circ}}^{521.31^{\circ}} \frac{\sin \left(2 \theta_{3}\right)}{\sin \left(\theta_{3}-\theta_{2}\right)} \mathrm{d} \theta_{2} .
$$

The integral in (15) was evaluated numerically by the use of the composite trapezoidal rule [23]. For $340^{\circ} \leq \theta_{2} \leq 520^{\circ}$, taken at one-degree intervals, the integral was evaluated as follows:

$$
\begin{aligned}
I_{1} & =\frac{1}{2}\left[f\left(340^{\circ}\right)+2 \sum_{\theta_{2}=341^{\circ}}^{\theta_{2}=519^{\circ}} f\left(\theta_{2}\right)+f\left(520^{\circ}\right)\right] \\
& =1,559.709 .
\end{aligned}
$$

For $520^{\circ} \leq \theta_{2} \leq 521.31^{\circ}$, taken as three unequal intervals, the integral was evaluated as follows:

$$
\begin{aligned}
& I_{2} \\
& =\left[\frac{f\left(520^{\circ}\right)+1.3 f\left(521^{\circ}\right)+0.31 f\left(521.3^{\circ}\right)+0.01 f\left(521.31^{\circ}\right)}{2}\right] \\
& =358.8177 .
\end{aligned}
$$

In (16) and (17), $f\left(340^{\circ}\right)$, for instance, is the value of $f\left(\theta_{2}\right)$ for the case where $\theta_{2}=340^{\circ}$. The total integral was then determined as follows:

$$
I=I_{1}+I_{2}=1,918.527 .
$$

Thus, the characteristic mechanical advantage was determined as follows:

$$
\bar{f}\left(\theta_{2}\right)=\frac{I}{181.31^{\circ}}=10.581
$$

From the preceding analysis, the force transmission characteristics for the PE 400 by 600 single toggle jaw crusher mechanism are summed up in Table 4.

The minimum force transmission ratio occurs at about the midpoint of the active crushing stroke, while the maximum force transmission ratio occurs at the end of the active crushing stroke. However, the force transmission ratio at the beginning of the active crushing stroke is also very highabout $74 \%$ of the value at the end of the crushing stroke.
Given a number of different mechanism designs, the characteristics given in Table 4 may be calculated for each candidate mechanism and used, among others, as criterion in the selection of a suitable jaw crusher mechanism for a given application.

\section{Conclusions}

A static force analysis of the single toggle jaw crusher mechanism was carried out. The method used is systematic, clear, and simple to follow and to use. As a result of the static force analysis, some force transmission characteristics of the single toggle jaw crusher mechanism were obtained. The analysis can also be used to determine the forces that are sustained by each of the components of the single toggle jaw crusher mechanism, provided that the values of the input torque and load torque are known.

An expression for the force transmission ratio of the single toggle jaw crusher mechanism was derived. By using the dimensional data of the PE 400 by 600 jaw crusher, the maximum value of the force transmission ratio was found to be about 3268, the minimum value of the force transmission ratio was found to be about 0.61 , and the mean value of the force transmission ratio was found to be about 10.6. These metrics can be used as criteria in the selection of a suitable mechanism design to be used in a given application, out of different alternatives.

The force transmission ratio was found to be very high at the beginning of the active crushing stroke, dropped off rapidly and then levelled off at about the minimum value, remained at the low value for about two-thirds of the active crushing stroke, and then rose rapidly to a very high value at the end of the active crushing stroke. The fact that the force transmission ratio is very high at the beginning of the active stroke is advantageous in crushing brittle materials which fracture without undergoing appreciable deformation.

\section{Competing Interests}

The authors declare that there is no conflict of interests regarding the publication of this paper.

\section{References}

[1] A. G. Erdman and G. N. Sandor, Mechanism Design: Analysis and Synthesis, vol. 1, Prentice-Hall, 1991.

[2] R. L. Norton, Design of Machinery: An Introduction to the Synthesis and Analysis of Mechanisms and Machines, McGraw-Hill, 1992.

[3] J. E. Shigley and J. J. Uicker Jr., Theory of Machines and Mechanisms, McGraw-Hill Book Company, 1980. 
[4] F. Freudenstein, "Approximate synthesis of four bar linkages," Transactions of the ASME, vol. 77, pp. 853-861, 1955.

[5] Z. Wang, H. Yu, D. Tang, and J. Li, "Study on rigid-body guidance synthesis of planar linkage," Mechanism and Machine Theory, vol. 37, no. 7, pp. 673-684, 2002.

[6] R.-C. Soong and S.-L. Wu, "Design of variable coupler curve four-bar mechanisms," Journal of the Chinese Society of Mechanical Engineers, vol. 30, no. 3, pp. 249-257, 2009.

[7] A. L. Mular, N. H. Doug, and D. J. Barrat, Mineral Processing Plant Design, Practice and Control: Proceedings, vol. 1, Society for Mining, Metallurgy and Exploration, 2002.

[8] The Institute of Quarrying Australia, Technical Briefing Paper No. 6: Crusher Selection III, https://www.quarry.com.au/files/ technical_papers/microsoft_word_-_technical_paper-no.6.doc .pdf.

[9] A. Carter Russell, "New Jaw Crushers are Reliable, Affordable and Transportable," Rock Products, 1999, http://www.rockproducts.com/index.php/features/51-archives/1240.pdf.

[10] C. W. Ham, E. J. Crane, and W. L. Rogers, Mechanics of Machinery, McGraw-Hill Book Company, 4th edition, 1958.

[11] G. H. Martin, Kinematics and Dynamics of Machines, McGrawHill, 2nd edition, 1982.

[12] C.-C. Lin and W.-T. Chang, "The force transmissivity index of planar linkage mechanisms," Mechanism and Machine Theory, vol. 37, no. 12, pp. 1465-1485, 2002.

[13] J. Denavit, R. S. Hartenberg, R. Razi, and J. J. Uicker, "Velocity, acceleration, and static-force analyses of spatial linkages," Journal of Applied Mechanics, vol. 32, no. 4, pp. 903-910, 1965.

[14] J. E. Holte and T. R. Chase, "A force transmission index for planar linkage mechanisms," in Proceedings of the ASME Mechanisms Conference, pp. 377-386, 1994.

[15] W.-T. Chang, C.-C. Lin, and J.-J. Lee, "Force transmissibility performance of parallel manipulators," Journal of Robotic Systems, vol. 20, no. 11, pp. 659-670, 2003.

[16] K. Abhary, "A simple analytical method for force analysis of planar frictional tree-like mechanisms," in Proceedings of the ASEE Annual Conference and Exposition, Pittsburgh, Pa, USA, 2008.

[17] J. T. Kimbrell, Kinematics Analysis and Synthesis, McGraw-Hill, 1991.

[18] K. Abhary, "A simple analytical method for teaching force analysis of planar frictionless mechanisms," in Proceedings of the ASME International Mechanical Engineering Congress and Exposition (IMECE '05), pp. 41-48, Orlando, Fla, USA, November 2005.

[19] M. F. Oduori, S. M. Mutuli, and D. M. Munyasi, "Analysis of the single toggle jaw crusher kinematics," Journal of Engineering, Design and Technology, vol. 13, no. 2, pp. 213-239, 2015.

[20] J. Cao, X. Rong, and S. Yang, "Jaw plate kinematical analysis for single toggle jaw crusher design," in Proceedings of the International Technology and Innovation Conference (ITIC '06), pp. 62-66, Hangzhou, China, November 2006.

[21] Zhengzhou Dingsheng Engineering Technology Company Limited, DSMAC PE Series Jaw Crusher Brochure, 2012, http:// www.dscrusher.com/pdf/Jaw-Crusher.pdf.

[22] R. E. Larson, R. P. Hostetler, and B. H. Edwards, Calculus with Analytical Geometry, chapter 4, D. C. Heath and Company, 1994.

[23] S. C. Chapra, Applied Numerical Methods with MATLAB for Engineers and Scientists, chapter 19, McGraw-Hill, 3rd edition, 2012. 


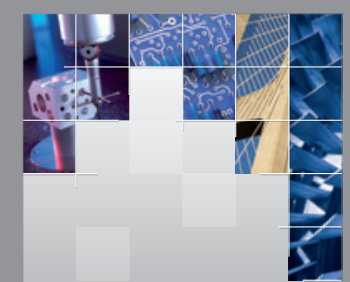

\section{Enfincering}
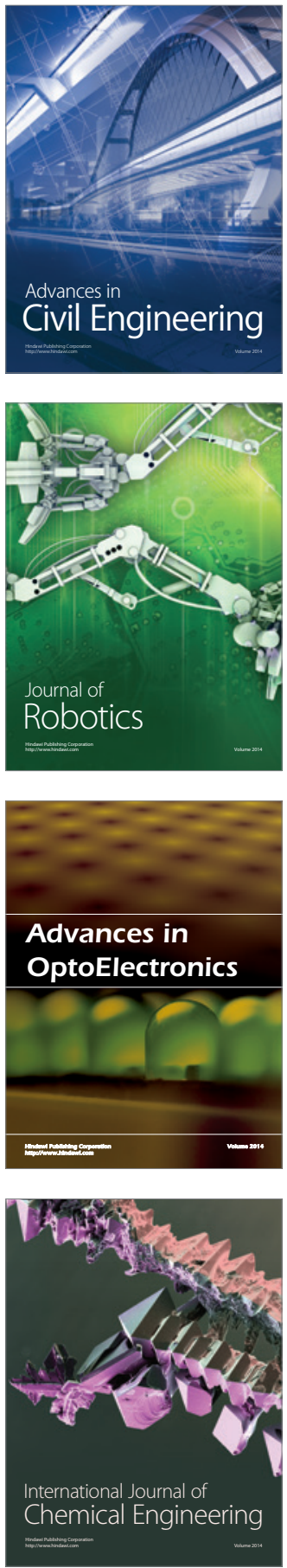

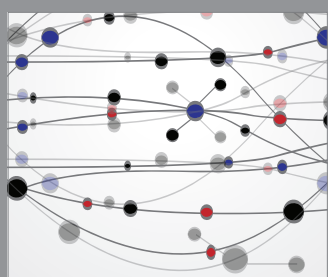

The Scientific World Journal

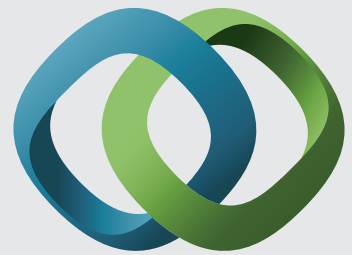

\section{Hindawi}

Submit your manuscripts at

http://www.hindawi.com
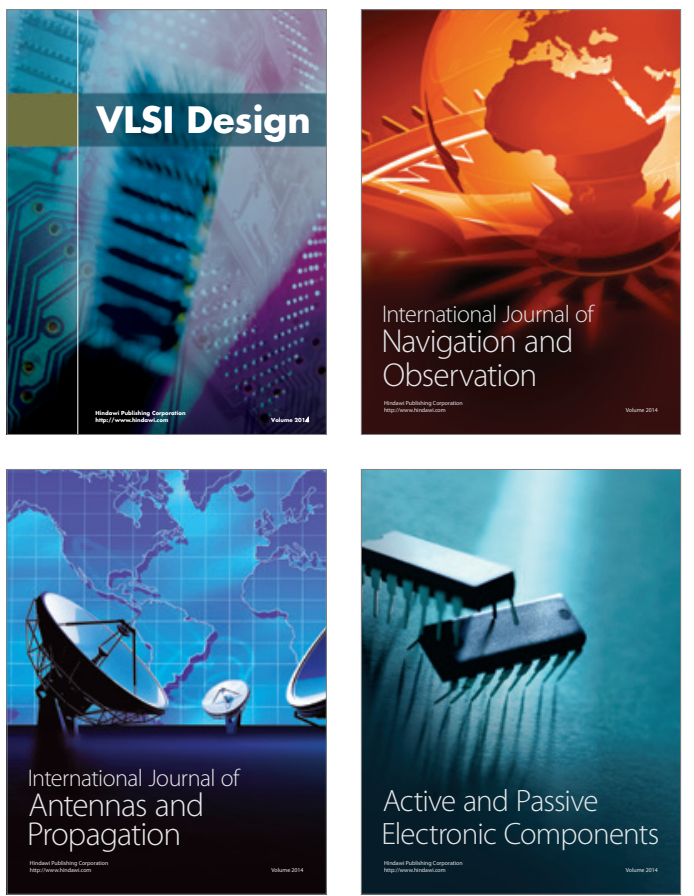
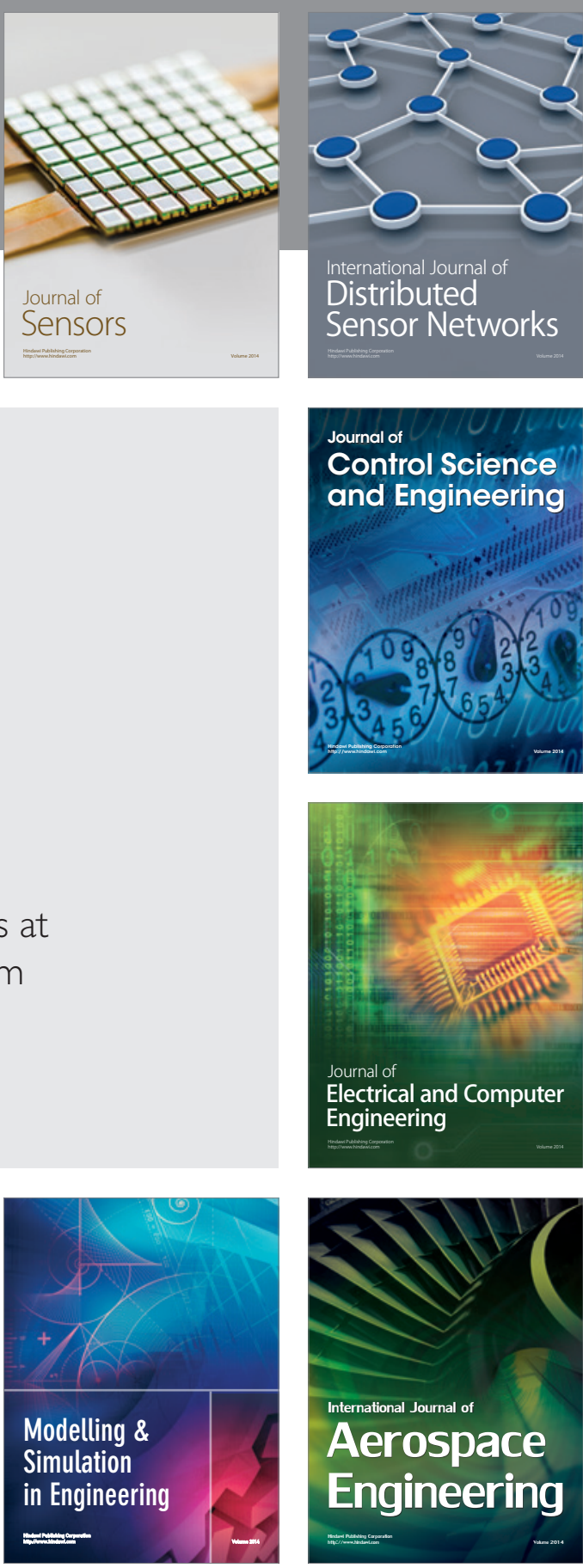

International Journal of

Distributed

Sensor Networks

Journal of

Control Science

and Engineering
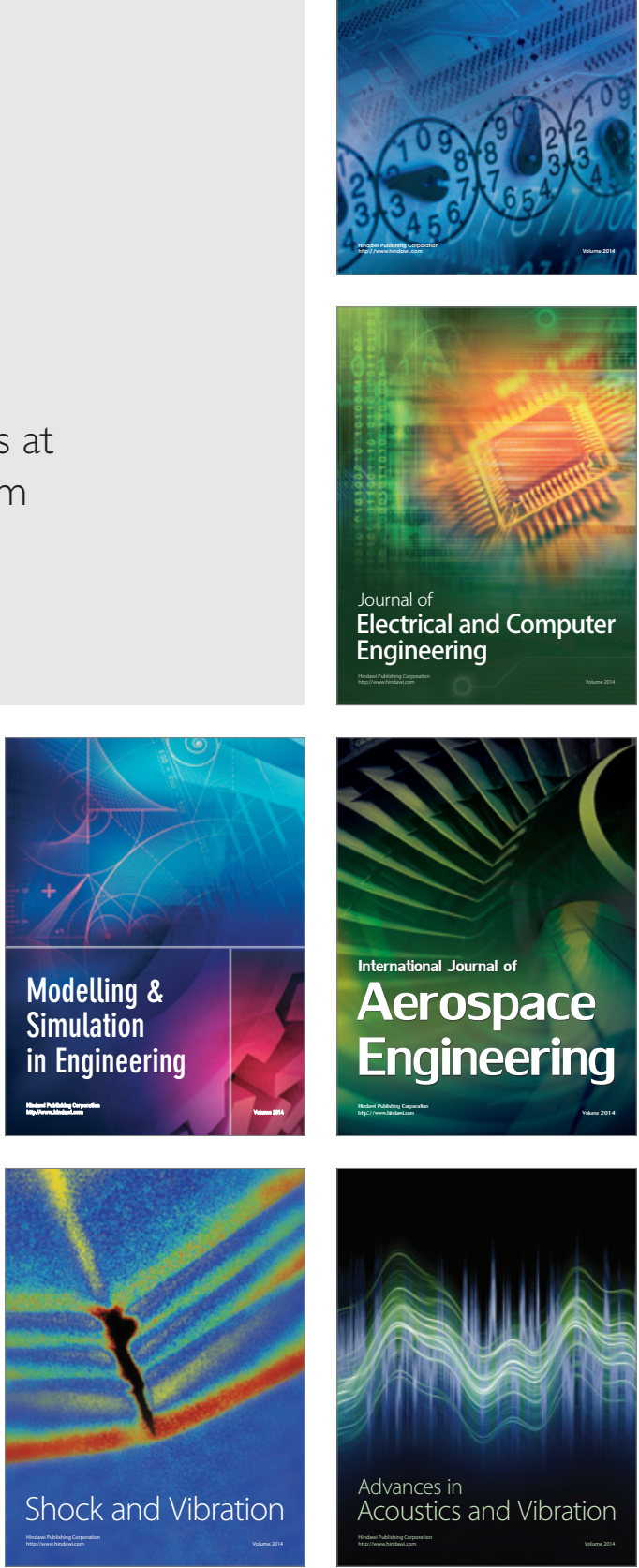